\title{
MCM5 as a target of BET inhibitors in thyroid cancer cells
}

\author{
Catia Mio', Elisa Lavarone', Ketty Conzatti', Federica Baldan', Barbara Toffoletto', \\ Cinzia Puppin', Sebastiano Filetti², Cosimo Durante ${ }^{2}$, Diego Russo 3 , \\ Arturo Orlacchio4, Antonio Di Cristofano4, Carla Di Loreto ${ }^{1}$ and Giuseppe Damante ${ }^{1}$ \\ ${ }^{1}$ Department of Medical and Biological Sciences, University of Udine, Udine, Italy \\ 2Department of Internal Medicine and Medical Specialties, University 'Sapienza', Rome, Italy \\ 3Department of Health Sciences, University of Catanzaro 'Magna Graecia', Catanzaro, Italy \\ ${ }^{4}$ Department of Developmental and Molecular Biology, Albert Einstein College of Medicine, Bronx, \\ New York, USA
}

Correspondence should be addressed to G Damante

Email

giuseppe.damante@uniud.it

\begin{abstract}
Anaplastic thyroid carcinoma (ATC) is an extremely aggressive thyroid cancer subtype, refractory to the current medical treatment. Among various epigenetic anticancer drugs, bromodomain and extra-terminal inhibitors (BETis) are considered to be an appealing novel class of compounds. BETi target the bromodomain and extra-terminal of BET proteins that act as regulators of gene transcription, interacting with histone acetyl groups. The goal of this study is to delineate which pathway underlies the biological effects derived from BET inhibition, in order to find new potential therapeutic targets in ATC. We investigated the effects of BET inhibition on two human anaplastic thyroid cancer-derived cell lines (FRO and SW1736). The treatment with two BETis, JQ1 and I-BET762, decreased cell viability, reduced cell cycle S-phase, and determined cell death. In order to find BETi effectors, FRO and SW1736 were subjected to a global transcriptome analysis after JQ1 treatment. A significant portion of deregulated genes belongs to cell cycle regulators. Among them, MCM5 was decreased at both mRNA and protein levels in both tested cell lines. Chromatin immunoprecipitation (ChIP) experiments indicate that MCM5 is directly bound by the BET protein BRD4. MCM5 silencing reduced cell proliferation, thus underlining its involvement in the block of proliferation induced by BETis. Furthermore, MCM5 immunohistochemical evaluation in human thyroid tumor tissues demonstrated its overexpression in several papillary thyroid carcinomas and in all ATCs. MCM5 was also overexpressed in a murine model of ATC, and JQ1 treatment reduced $M c m 5$ mRNA expression in two murine ATC cell lines. Thus, MCM5 could represent a new target in the therapeutic approach against ATC.
\end{abstract} Key Words

\section{Introduction}

Thyroid cancers are the most widespread malignancies of the endocrine system and represent approximately $1-1.5 \%$ of all tumor-related diseases. The overall 5-year survival of these tumors is approximately 85-90\%, with the highest mortality rate reported for poorly differentiated histotypes (Durante et al. 2006, Patel \& Shaha 2014). Anaplastic thyroid carcinomas (ATCs), which are wholly or partially composed of undifferentiated cells arising from thyroid follicular epithelium, represent the least common but most lethal thyroid cancer subtype.

Published by Bioscientifica Ltd 
Indeed, they are characterized by genetic and epigenetic aberrations that make them unresponsive to treatments based on radioiodine administration (Arturi et al. 2000, Schlumberger et al. 2007, Perri et al. 2011, Elisei 2012). Thus, innovative approaches for ATC treatment are required.

The term 'epigenetics' is commonly used to describe the study of hereditable changes in gene expression that are independent from alteration in the underlying DNA sequence. As aberrant gene expression is an essential characteristic that distinguishes neoplastic cells from normal ones, compounds able to target epigenetic alterations are becoming increasingly appealing for cancer treatment. Most of these molecules act on epigenetic 'writers' or 'erasers', that is, enzymes regulating DNA or histone covalent modifications. Notably, compounds targeting enzymes involved in DNA methylation and histone acetylation have been greatly investigated in several experimental models of solid tumors, including thyroid cancer (Puppin et al. 2005, Russo et al. 2013). Several other chromatin regulators, instead, act as 'readers': they possess peculiar domains that are able to interact with nucleosome covalent modifications and respond to upstream signal cascades to control gene expression (Dawson et al. 2012). A rising class of compounds that are able to target chromatin readers is called BET inhibitors (BETis). BET is the acronym of bromodomain and extra-terminal family of proteins (Nicodeme et al. 2010). The mammalian BET protein family includes four members: BRD2, BRD3, and BRD4, which are ubiquitously expressed, and BRDT, whose expression is confined to germ cells. These proteins possess a tandem bromodomain at the $\mathrm{N}$-terminal region, by which they interact with histone acetyl-lysines in order to control gene transcription and cell proliferation (Chiang 2009). Due to the relevance of BET proteins, several inhibitors have been recently developed (Filippakopoulos et al. 2010, Nicodeme et al. 2010). BETis hinder proliferation of a wide range of hematopoietic malignant cell lines and nuclear protein in testis (NUT) midline carcinoma-derived cells (Filippakopoulos et al. 2010, Zuber et al. 2011). The use of BETis, as well as the use of other epigenetic compounds, might be a complicate issue in cancer treatment because these drugs act on a large spectrum of genes (Falahi et al. 2015). However, the antiproliferative outcome could be reasonably due to the deregulation of only a small subset of genes. For instance, repression of the $c-M Y C$ oncogene seems to play a major role in mediating the effects of BETis in leukemic cells (Ott et al. 2012). Thus, an attractive approach to study epigenetic compounds is to define their critical effector genes. For this purpose, in this study we investigated the effects of BET inhibition in two human ATC cell lines, analyzing the modulation of their global gene expression profiles. By using this approach, we propose MCM5 as a potential new target for ATC treatment.

\section{Materials and methods}

\section{Human and murine cell lines}

FRO (purchased from the European Collection of Cell Cultures, Salisbury, UK) and SW1736 (obtained from Cell Lines Service GmbH, Eppelheim, Germany) are human cell lines derived from ATC, both harboring a BRAF V600E mutation (Schweppe et al. 2008, Pilli et al. 2009). Both cell lines have been tested for being mycoplasma free and authenticated by short tandem repeats (STR) analysis to be appropriate cell lines of thyroid cancer origin. FRO and SW1736 were grown in DMEM medium (EuroClone, Milan, Italy) and RPMI 1640 medium (EuroClone), respectively, supplemented with 10\% fetal bovine serum (Gibco Invitrogen, Milan, Italy), $2 \mathrm{mM}$ l-glutamine (EuroClone), and $50 \mathrm{mg} / \mathrm{mL}$ gentamicin (Gibco Invitrogen), in a humidified incubator $\left(5 \% \mathrm{CO}_{2}\right.$ in air at $\left.37^{\circ} \mathrm{C}\right)$. Cultured cells were treated with vehicle (DMSO, Sigma-Aldrich, St Louis, $\mathrm{MO}$, USA) or the following agents: JQ1 $(50 \mathrm{nM}-10 \mu \mathrm{M}$ in DMSO) (Cayman Chemical, Ann Arbor, MI, USA) and I-BET762 (50 nM-10 $\mu \mathrm{M}$ in DMSO) (Merck Millipore). T4888M and T3531L are ATC cell lines derived from tumors developed by [Pten, Tp53 $]^{\text {thyr- } /-}$ mice (Antico Arciuch et al. 2011). Cells were grown in DMEM supplemented with 10\% FBS.

\section{Animals}

[Pten, Tp53 $]^{\text {thyr- } / \text { - }}$ and Pten ${ }^{\text {thyr-l- }}$ mice have been as described previously (Yeager et al. 2007, Antico Arciuch et al. 2010, 2011). The animals were housed in the Albert Einstein College of Medicine animal facility under specific pathogen-free conditions.

\section{Cell viability and apoptosis}

To test cell viability, an MTT assay was performed as described previously (Baldan et al. 2014). Briefly, 5000 cells were seeded onto 96-well plates. On the next day, the growth medium was replaced with vehicle-treated medium (NT, untreated cultures) or with medium containing JQ1

Published by Bioscientifica Ltd 
or I-BET762; plates were incubated for $0,24,48$, and $72 \mathrm{~h}$. All experiments were run in quadruplicate and cell viability was expressed as a percentage relative to baseline samples (T0). The percentage of cell viability assessed by MTT assay was used to determine $\mathrm{EC}_{50}$ concentrations from dose-response curves after $72 \mathrm{~h}$ treatment.

Caspase 3/7 activity was measured as a marker of apoptosis using the Apo-ONE Homogeneous Caspase-3/7 Assay Kit (Promega, Milan, Italy) according to the manufacturer's protocol. Five thousand cells were seeded onto 96-well plates. On the next day, the growth medium was replaced with vehicle-treated medium (NT, untreated cultures) or medium containing JQ1 $5 \mu \mathrm{M}$ or I-BET762 $5 \mu \mathrm{M}$; the plates were incubated for $48 \mathrm{~h}$. All experimental points were run in triplicate, and apoptosis levels were expressed as a percentage relative to baseline samples (NT).

\section{Cell cycle analysis}

Cell cycle was determined by fluorescence-activated cellsorting (FACS) analysis of DNA content. Briefly, FRO and SW1736 cells were collected after a 24,48 , and $72 \mathrm{~h}$ treatment with either JQ1 or vehicle (NT); the cells were fixed in cold ethanol $70 \%$ and stained with propidium iodide solution containing RNase and Triton-X100. Flow cytometric analysis was performed on a FACSCalibur (Becton Dickinson, Franklin Lakes, NY, USA) using ModFit LT analysis software (Verity Software House, Inc., Topsham, ME, USA). A minimum of 20,000 cells was analyzed for each sample. All experiments were run in triplicate.

\section{High-throughput RNA sequencing and analysis}

About $1.5 \mu \mathrm{g}$ of good-quality RNA (RNA Integrity Number $>7$ ) was used as a starting material for preparation of library using the Illumina mRNASeq Sample Prep Kit v2.0, following the manufacturer's instructions (Illumnina, San Diego, CA, USA). The poly-A mRNA was fragmented for $1.5 \mathrm{~min}$ at $94^{\circ} \mathrm{C}$, and all purification steps were performed by using $1 \mathrm{X}$ Agencourt AMPure XP beads (Beckman Coulter, Brea, CA, USA). Quality and quantity of each library were assessed by using an Agilent 2100 Bioanalyzer High Sensitivity and Qubit DNA High Sensitivity (Invitrogen). The libraries were pooled together and the obtained pool was checked on an Agilent Bioanalyzer 2100 in order to determine the molarity. Single-read sequencing was performed on the HiSeq2000 (Illumina, San Diego, CA, USA) generating 50-base reads.
The CASAVA 1.8.2 version of the Illumina pipeline was used for image analysis, base calling, and demultiplexing. Reads were first trimmed in order to remove lower base quality data with ERNE (extended randomized numerical aligner) (Vezzi et al. 2012), and adapter sequences were removed with cutadapt (https://pypi.python.org/pypi/ cutadapt/1.3). TopHat (Trapnell et al. 2012) was used for mapping and annotation on the HG19 reference sequence. Differential gene expression analysis was performed according to the experimental design using Cufflinks (Trapnell et al. 2012).

\section{Gene expression assays}

Total RNA from human cell lines, treated with either JQ1 $5 \mu \mathrm{M}$ or vehicle, was extracted with the RNeasy Mini Kit (Qiagen) according to manufacturer's instructions. About $500 \mathrm{ng}$ of total RNA were reverse transcribed to cDNA using random exaprimers and MMLV reverse transcriptase (Life Technologies). Real-time PCRs were performed using Platinum SYBR Green qPCR SuperMix (Life Technologies) with the ABI Prism 7300 Sequence Detection Systems (Applied Biosystems). The $\Delta \Delta C T$ method, by means of the SDS software (Applied Biosystems), was used to calculate mRNA levels. Oligonucleotide primers for MCM5 (forward, 5'-GATCCTGGCATTTTCTACAG-3'; reverse, 5'-CCCTGTATTTGAAGGTGAAG-3') and $\beta$-actin (forward, 5'-TTGTTACAGGAAGTCCCTTGCC-3'; reverse, 5'-ATGCTATCACCTCCCCTGTGTG-3') were purchased from Sigma-Aldrich.

Total mouse RNA (treated with either $0.5 \mu \mathrm{M}$ or vehicle) was extracted with Trizol and reverse transcribed using the Maxima First Strand cDNA Synthesis Kit (Thermo Scientific). qRT-PCR was performed on a StepOnePlus apparatus using SYBR Green PCR Master Mix (Applied Biosystems) and custom-designed primers (forward, 5'-CAGAGGCGATTCAAGGAGTTC-3'; reverse, 5'-CGATCCAGTATTCACCCAGGT-3). Each sample was run in triplicate and $18 S$ was used to control for input RNA. Data analysis was based on the $\mathrm{C}_{\mathrm{T}}$ method, and experiments were repeated at least three times using at least two independent organ and cell pools.

\section{Chromatin immunoprecipitation}

The chromatin immunoprecipitation (ChIP) assay was performed as described previously (Baldan et al. 2015). For immunoprecipitation, samples were incubated with $10 \mu \mathrm{g}$ of rabbit polyclonal anti-BRD4 (Active Motif, Carlsbad, CA, USA) or Rabbit IgG (Millipore) as negative control (NC).

Published by Bioscientifica Ltd. 
After incubation with Dynabeads Protein A (Invitrogen), washing, and elution, the DNA was extracted with phenol/chloroform, and the aqueous phase recovered and precipitated. The extracted DNA was used as a template in qPCR with the following primers: MCM5 Forward Primer (CCTGTTCTGGCCGTTTGTTC), MCM5 Reverse Primer (GATCGTCGAATCCCGACATG); NCR Forward Primer (TGCTGTTACTTTTTACAGGGAGTT), NCR Reverse Primer (TTTGAGCAAAATGTTGAAAACAA). Fold enrichment was, then, calculated as signal over background (IgG). Data are representative of three different experiments.

\section{RNA silencing}

For transient silencing of endogenous MCM5, the TriFECTa RNAi Kit (Integrated DNA Technologies, Inc., Coralville, IA, USA) was used. A 'universal' NC duplex that targets a site that is absent from human, mouse, and rat genomes was used. siRNA oligonucleotides were transfected at a concentration of $5 \mathrm{nM}$ using DharmaFECT Transfection reagent (Thermo Scientific), according to the manufacturer's instructions. The day before transfection, cells were plated in antibiotics-free medium and harvested $72 \mathrm{~h}$ after transfection. The gene-silencing efficiency was evaluated by mRNA and protein level analysis.

\section{Annexin V assay}

In other to test the percentage of viable/apoptotic cells after MCM5 silencing, an Annexin V assay was performed. Briefly, cells were washed with cold PBS, transferred to a polystyrene round-bottomed flow tube (Falcon; Becton Dickinson), and resuspended in $195 \mu \mathrm{L}$ of 1 binding buffer (BB $10 \mathrm{mM}$; HEPES/ $\mathrm{NaOH}, \mathrm{pH} 7.4$, $140 \mathrm{mM} \mathrm{NaCl}$, and $2.5 \mathrm{mM} \mathrm{CaCl}$ ). Five microliter of Fluorescein-conjugated Annexin V (Annexin V-FITC; Bender Med Systems, Vienna, Austria) was added and samples were incubated for $10 \mathrm{~min}$ at room temperature. After washing, cells were resuspended in $190 \mu \mathrm{L}$ of BB in which $10 \mu \mathrm{L}$ of propidium iodide stock solution (final concentration $1 \mu \mathrm{g} / \mathrm{mL}$ ) was added. Flow cytometric analysis was done on CyAN, Dako Cytomation using Summit software (flow cytometer; Beckman Coulter). Forward scatter and side scatter were acquired in a linear mode. FITC and PI fluorescent signals derived from $488 \mathrm{nM}$ excitation were detected in a logarithmic mode at FL1/PMT3 and FL2/PMT4, with FITC 530/30 nM filters and PI 585/42 nM filters, respectively, and a FL1/2 $560 \mathrm{nM}$ shortpass dichroic filter. Signals for forward and side scatter and fluorescence were collected for $10^{4}$ cells using the forward light scatter parameter as the master signal. Data are expressed as mean fluorescence intensity (FI) values. All experiments were run in triplicate.

\section{MCM5 overexpression}

To overexpress MCM5 protein, we purchased the TrueClone MCM5 cDNA cloned in pCMV6-AC, which contains a full open reading frame of the human MCM5 gene (Origene, Rockville, MD, USA). The overexpression vector was transfected with Turbofect reagent (Fisher Scientific S.A.S., Illkirch, France) at $2 \mu \mathrm{L}$ per well. pCMV empty vector was used as NC. Once we verified the overexpression by immuonoblotting, we performed a rescue experiment, in order to verify the direct involvement of MCM5 in JQ1 mechanism of action. Cells were transfected with pCMV-MCM5 or NC and exposed to $5 \mu \mathrm{M} \mathrm{JQ} 1$ or vehicle for $48 \mathrm{~h}$. Cell viability was evaluated by MTT assay, as described previously.

\section{Protein extraction and Western blot}

Total protein extraction was performed as described previously (Passon et al. 2012). Briefly, FRO and SW1736 cells, incubated in vehicle-treated medium (NT, untreated cultures) or with JQ1 $5 \mu \mathrm{M}$, were harvested by scraping and lysed with total lysis buffer (Tris- $\mathrm{HCl} 50 \mathrm{mM}$ pH8, $\mathrm{NaCl} 120 \mathrm{mM}$, EDTA $5 \mathrm{mM}$, Triton 1\%, NP40 1\%, protease inhibitors). For subcellular fractionation, pellets were resuspended in buffer A (10 mM Tris- $\mathrm{HCl}$ ( $\mathrm{pH} 7.5), 1.5 \mathrm{mM}$ $\mathrm{MgCl}_{2}$, and $10 \mathrm{mM} \mathrm{KCl}$ supplemented with $1 \times$ protease inhibitor cocktail, $0.5 \mathrm{mM}$ PMSF, $1 \mathrm{mM} \mathrm{NaF}$, and $1 \mathrm{mM}$ $\mathrm{Na}_{3} \mathrm{VO}_{4}$ ) and centrifugated at $2000 \mathrm{~g}$ for $10 \mathrm{~min}$ at $4^{\circ} \mathrm{C}$. For nuclear extracts collection, pellets were resuspended in buffer B (20 mM Tris- $\mathrm{HCl}$ (pH 7.5), $0.42 \mathrm{M} \mathrm{KCl}, 1.5 \mathrm{mM}$ $\mathrm{MgCl}_{2}, 20 \%$ (vol/vol) glycerol supplemented with $1 \times$ protease inhibitor cocktail, $0.5 \mathrm{mM}$ PMSF, $1 \mathrm{mM} \mathrm{NaF}$, and $1 \mathrm{mM} \mathrm{Na} \mathrm{VO}_{4}$ ) and centrifuged at $15,000 \boldsymbol{g}$ for $30 \mathrm{~min}$ at $4^{\circ} \mathrm{C}$. For western blotting analysis, proteins were electrophoresed on 10\% SDS-PAGE and then transferred to nitrocellulose membranes, which were saturated with 5\% nonfat dry milk in PBS/0.1\% Tween 20 . The membranes were then incubated overnight with rabbit polyclonal anti-BRD4 antibody 1:1000 (Active Motif), rabbit anti-lamin- $\beta 1$ antibody 1:1000 (Abcam), rabbit polyclonal anti-MCM5 antibody 1:250 (Sigma-Aldrich), or rabbit anti- $\beta$-actin antibody 1:1000 (Abcam). The next day, membranes were incubated for $2 \mathrm{~h}$ with anti-rabbit immunoglobulin coupled to peroxidase 1:4000 (Sigma-Aldrich). The blots were developed using

Published by Bioscientifica Ltd 
Uvitec Alliance LD (UVItec Limited, Cambridge, UK) with the SuperSignal Technology (Thermo Fisher Scientific).

\section{Human tissues and immunohistochemistry}

A series of 12 normal thyroid glands (NTs), 25 follicular adenomas (FAs), 23 follicular thyroid carcinomas (FTCs), 36 papillary thyroid carcinomas (PTCs), and eight ATCs were selected from the files of the Institution of Anatomic Pathology of the University of Udine (Udine, Italy), and the most representative block of each lesion was retrieved from the archive. Representative tumor-bearing areas were selected and a tissue microarray was constructed. All samples were diagnosed by referral pathologists of the institution and then reviewed by a single experienced pathologist, thus including only patients with a confirmed diagnosis. Briefly, $5 \mu \mathrm{M}$ formalin-fixed paraffin tissue sections mounted on SuperFrost Plus slides (Menzel-Gläser, Braunschweig, Germany) were placed in the PT Link pre-treatment module (DAKO A/S, Glostrup, Denmark), which performs automatically the entire pretreatment process of de-paraffinization, rehydration, and epitope retrieval using the Low $\mathrm{pH}$ Target Retrieval Solution $(0.001 \mathrm{M}$ citrate buffer $\mathrm{pH} 6.0)$ at $98^{\circ} \mathrm{C}$ for $40 \mathrm{~min}$ from DAKO. Endogenous peroxidase activity was blocked by incubation using the peroxidase block solution (DAKO) for $5 \mathrm{~min}$. Primary rabbit polyclonal antiserum to MCM5 (Sigma-Aldrich) diluted 1:1000 was applied and incubated for $60 \mathrm{~min}$ at room temperature. After washing, the slides were incubated with the DAKO EnVision FLEX System (DAKO) according to the manufacturer's guidelines. For reaction visualization, 3,3'-diaminobenzidine tetrahydrochloride was used as chromogen. The sections were counterstained with Mayer's hematoxylin. Using light microscopy, the entire section was scanned at high-power magnification $(400 \times)$ and nuclear immunostaining was evaluated semiquantitatively as percentage of positive cells. Staining intensity was scored as light, moderate, and strong. A final score was then calculated by multiplying the percent staining by the intensity level.

\section{Statistical analysis}

mRNA and protein levels, cell viability, and apoptosis levels were expressed as means \pm S.D., and significances were determined by a one-way ANOVA followed by Dunnett's test performed with GraphPAD Software for Science. ${ }^{*} P$ value $<0.05$ was considered to be statistically significant.

\section{Results}

\section{Biological effects of BETis on ATC cells}

In a first set of experiments, we evaluated the sensitivity of two human anaplastic thyroid cancer cell lines (FRO and SW1736) to BETis. As shown in Fig. 1, incubation either with JQ1 (Fig. 1A) or I-BET762 (Fig. 1B) significantly reduced FRO and SW1736 cell viability at different time points. Relying on data obtained, for further experiments, we decided to use the median effective dose of $5 \mu \mathrm{M}$; i.e., the dose required to achieve $50 \%$ of the desired response in $50 \%$ of the population. To assess whether the decrease in cell viability was due to an increase of apoptotic cell death, caspase 3/7 levels were measured after $48 \mathrm{~h}$ treatment. Administration of JQ1 increased caspase levels in both cell lines in a quite striking manner, whereas I-BET762 treatment showed a less pronounced effect (Fig. 1C). In order to verify whether a $48 \mathrm{~h}$ I-BET762 treatment displayed a caspase-independent cell death, we perform a western blotting analysis of PARP. PARP is known to be a substrate for several proteins such as caspases, calpains, and cathepsins; it produces several specific cleavage fragments that resemble signature patterns of different cell death programs (Gobeil et al. 2001; Chaitanya et al. 2010). As shown in Supplementary Fig. 2 see section on supplementary data given at the end of this article (Fig. 2A and B), ATC cells showed a marked increase of both apoptotic- and necrotic-specific cleaved-PARP. We, then, corroborated the BET inhibition effects on cell viability and cell death in $8505 \mathrm{c}$ cells, a third anaplastic thyroid cell line (Supplementary Fig. 3). Moreover, we used a third BETi: I-BET151. This latter is a pan-BETi having a slight different chemical structure compared to I-BET762. I-BET151 reduced cell viability similarly to I-BET762 (Supplementary Fig. 1A and B, and Supplementary Fig. 3). Hereinafter, we decided to proceed in our investigation with JQ1-treatment only, as it revealed to be the most effective drug, in terms of biological effects, in both cell lines. A FACS analysis of the cell cycle was then performed on both cell lines treated with $5 \mu \mathrm{M}$ JQ1 for 24,48 , and $72 \mathrm{~h}$. JQ1-treatment significantly increased the proportion of cells arrested in G0/G1 at each analyzed time point (Fig. 1D).

\section{Differential gene expression after BET inhibition}

To identify potential molecular targets connected to BET inhibition, we performed a high-throughput RNA sequencing (RNA-seq) analysis on both FRO and SW1736 cells treated with $5 \mu \mathrm{M}$ JQ1 or vehicle for $24 \mathrm{~h}$. To assess

Published by Bioscientifica Ltd 
A

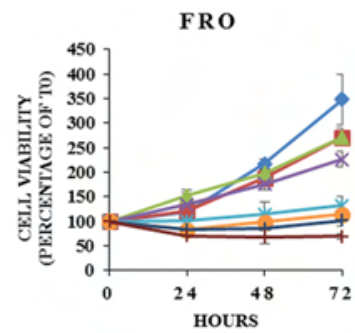

B

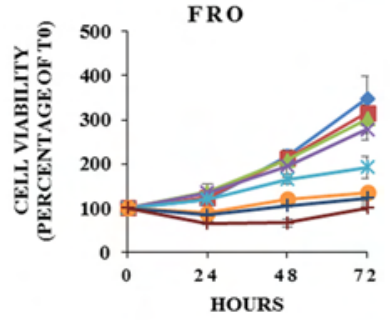

C
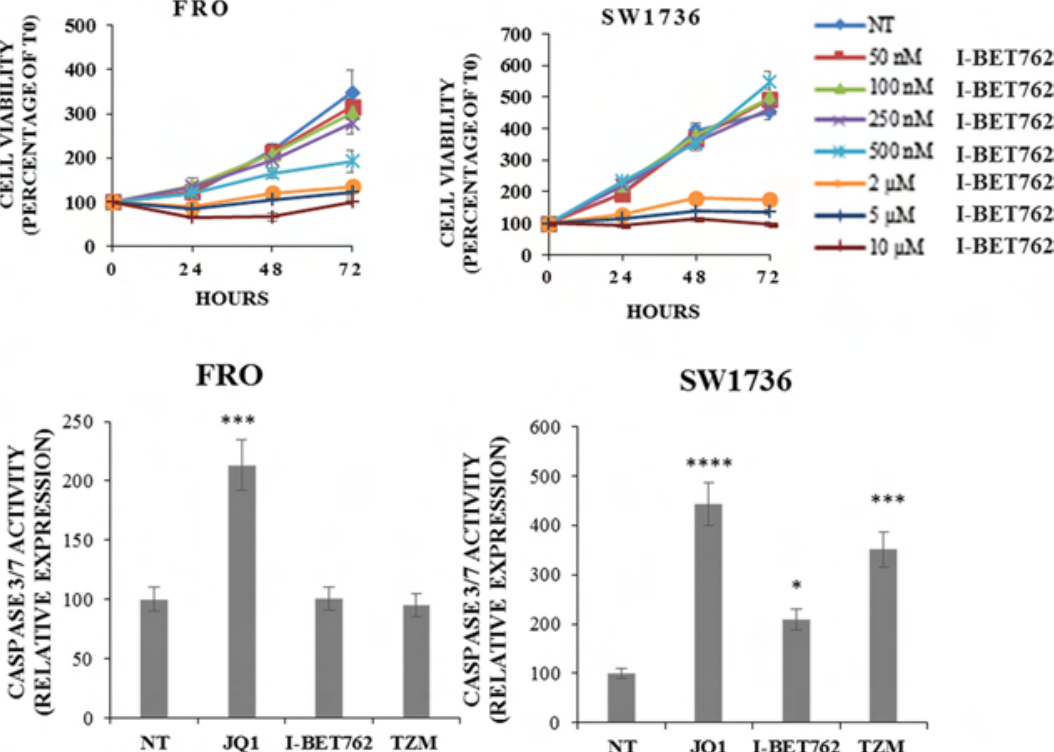

SW1736

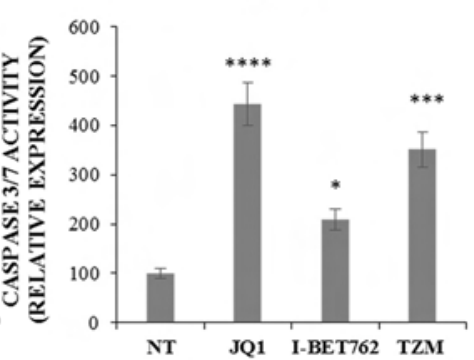

D

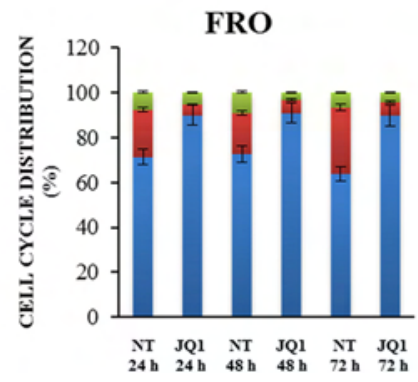

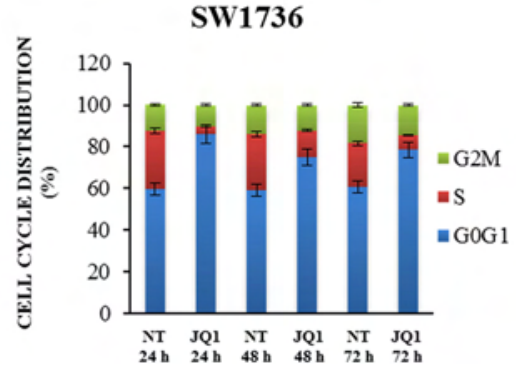

Figure 1

BETis administration decreases proliferation and survival of ATC cell lines. (A and B) FRO and SW1736 were exposed to JQ1 or I-BET762 different doses (rising from $50 \mathrm{nM}$ to $10 \mu \mathrm{M}$ ). Cell viability was determined by the MTT assay after $0,24,48$, and $72 \mathrm{~h}$ and expressed as a percentage of baseline samples (TO). All samples were run in quadruplicate. (C) Apoptosis levels were evaluated $48 \mathrm{~h}$ after treatment with either $5 \mu \mathrm{M}$ BETis or vehicle (NT). Caspase $3 / 7$ levels were normalized to the vehicle-treated group. Temozolomide $(500 \mu \mathrm{M})$, a chemotherapy drug, was used as a positive control for apoptosis. Each sample was run in triplicate. ${ }^{*} P<0.05$, $* * * P<0.001, * * * * P<0.0001$ by ANOVA test. (D) FRO and SW1736 cell cycle distribution was determined after $5 \mu \mathrm{M}$ JQ1 or vehicle administration. Cells were collected after 24,48 , and $72 \mathrm{~h}$ treatments. Data are representative of three independent experiments. the transcriptional changes induced by BET inhibition, a comparison between cells treated with JQ1 or vehicle was performed. Heat maps representing each analyzed condition are shown in Fig. 2A. Expression of 14,199 and 13,013 genes was detected in FRO and SW1736 cell lines, respectively. Vehicle-treated (NT) FRO and SW1736 cells showed a quite different mRNA profile. After filtering low quantity reads, results showed that approximately 2000 genes were differentially expressed after JQ1 treatment either in FRO or SW1736 cells (at a $\log _{2}$ fold change $>2$ ) (Supplementary Tables 1 and 2, see section on supplementary data given at the end of this article). Among them, 768 genes were significantly upregulated and 1229 were downregulated in response to JQ1 treatment (Fig. 2B). Venn diagrams showed that the majority of altered genes was specific for each cell line, which likely underlies the differential mRNA profile observed with vehicle treatment. However, there was a core set of 288 genes commonly affected by JQ1 treatment in both cell lines, most of which decreased their expression $(n=213)$. RNA-seq data, then, were confirmed by qPCR (Supplementary Fig. 4). The shared top 20 differentially expressed genes (Table 1) were then subjected to Ingenuity Pathway Analysis in order to outline which pathways were mostly affected by JQ1 treatment. Various signaling cascades turned out to be modified by BETis treatment: regulation of DNA and metabolic processes proved out to be the most deregulated one (Supplementary Table 3). The RNA-seq analysis identified a large number of JQ1 putative targets, primarily in cell cycle-linked pathways.

Published by Bioscientifica Ltd 
$\mathbf{A}$

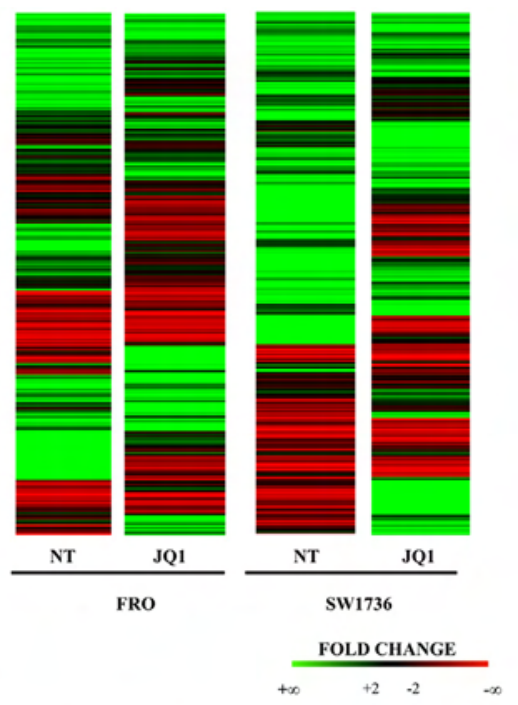

B UP-REGULATED GENES

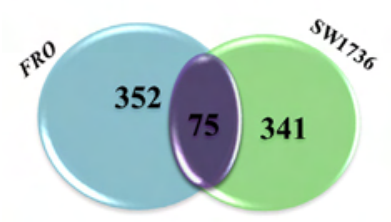

DOWN-REGULATED GENES

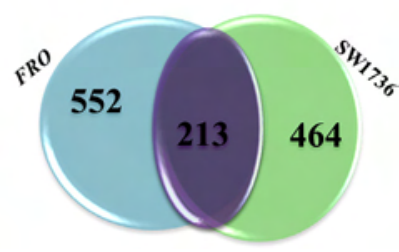

Figure 2

Gene expression modifications in ATC JQ1-treated cell lines. (A) Heat maps showing the hierarchical clustering of mRNA targets in FRO and SW1736 cell lines $(n=1997)$. Cells were treated with either $5 \mu \mathrm{M}$ JQ1 or vehicle for $24 \mathrm{~h}$. (B) Venn diagrams representing the comparison of both upregulated (left) and downregulated (right) genes between FRO and SW1736 cell lines after RNA-seq data analysis. Purple gene clusters represent shared modified genes between FRO and SW1736 cell lines.

These data are consistent with Da Costa's findings in leukemia cells (Da Costa et al. 2013). Several studies have proposed a possible role of $c-M Y C$ downregulation as a major mechanism of action of BETis (Alderton 2011, Zuber et al. 2011). Our RNA-seq data show that this oncogene is not a critical factor in JQ1-mediated effects in ATC cells, because JQ1 treatment did not significantly affect $c-M Y C$ expression in neither of the two cell lines (Supplementary Fig. 4). BETis, however, modified the expression of several cell cycle regulators such as RB proteins, E2F transcription factors, and CDK inhibitors (Supplementary Table 4).

\section{BETis effects on MCM5}

Considering that cell cycle regulatory genes were the most affected by JQ1 treatment, we focused on MCM5, one of the top 20 downregulated genes, which is known to be involved in G1/S cell cycle transition,

A

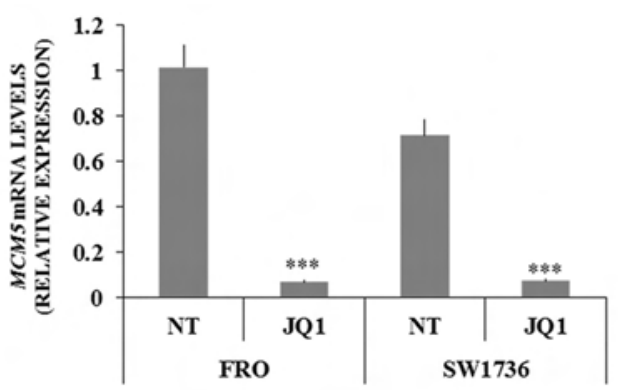

B

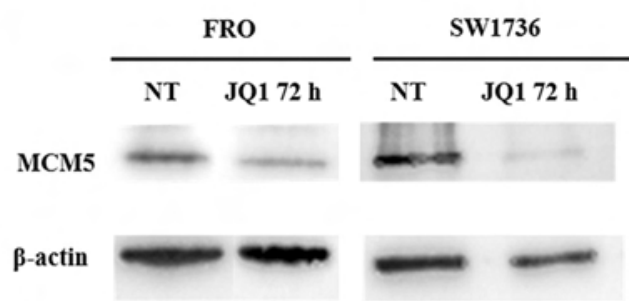

C

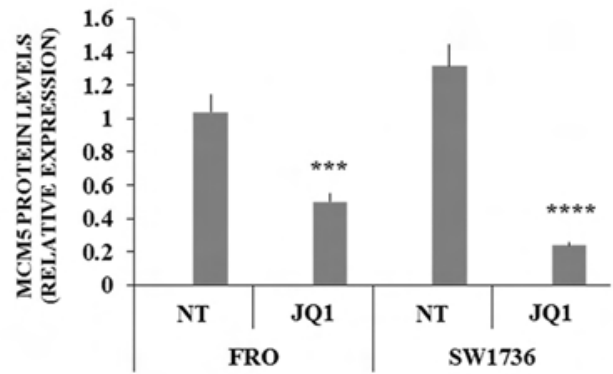

D

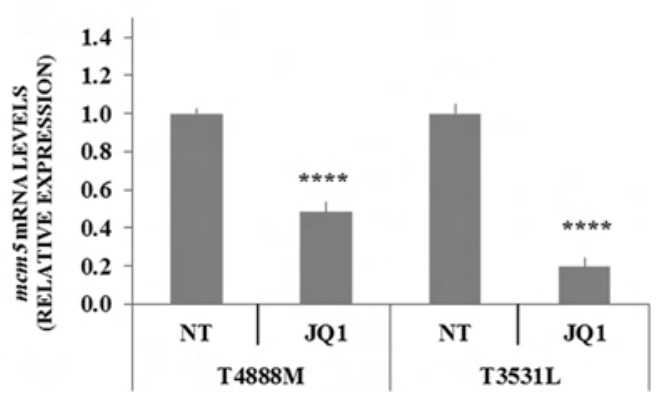

Figure 3

Downregulation of MCM5 in human and murine ATC cell lines after JQ1 treatment. (A) FRO and SW1736 cells were treated either with $5 \mu \mathrm{M}$ JQ1 or vehicle for $24 \mathrm{~h}$, and MCM5 mRNA expression was evaluated by qPCR. All samples were run in triplicate. Vehicle-treated (NT) FRO cells were arbitrarily set at 1.0 and mRNA levels are expressed as relative expression values. (B) FRO and SW1736 were treated with either $5 \mu \mathrm{M}$ JQ1 or vehicle for $72 \mathrm{~h}$, and MCM5 protein levels were detected by western blotting. (C) Densitometric analysis of MCM5 protein levels in ATC cells after $5 \mu \mathrm{M}$ JQ1 or vehicle treatment. (D) T4888M and T3531L cells were treated with either $0.5 \mu \mathrm{M}$ JQ1 or vehicle for $72 \mathrm{~h}$, and $\mathrm{Mcm} 5 \mathrm{mRNA}$ expression was evaluated by qPCR. All samples were run in triplicate. Vehicle-treated (NT) T4888M cells were arbitrarily set at 1.0 and mRNA levels are expressed as relative expression values. Results are shown as mean \pm S.D. $* * * P<0.001, * * * * P<0.0001$ by ANOVA test. Data are representative of three independent experiments.

Published by Bioscientifica Ltd 
A

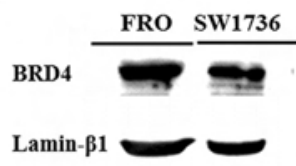

C
(1)
FRO
MOCK NC SIRNA\#1 SIRNA\#2 SIRNA\#3
MOCK NC
SW1736
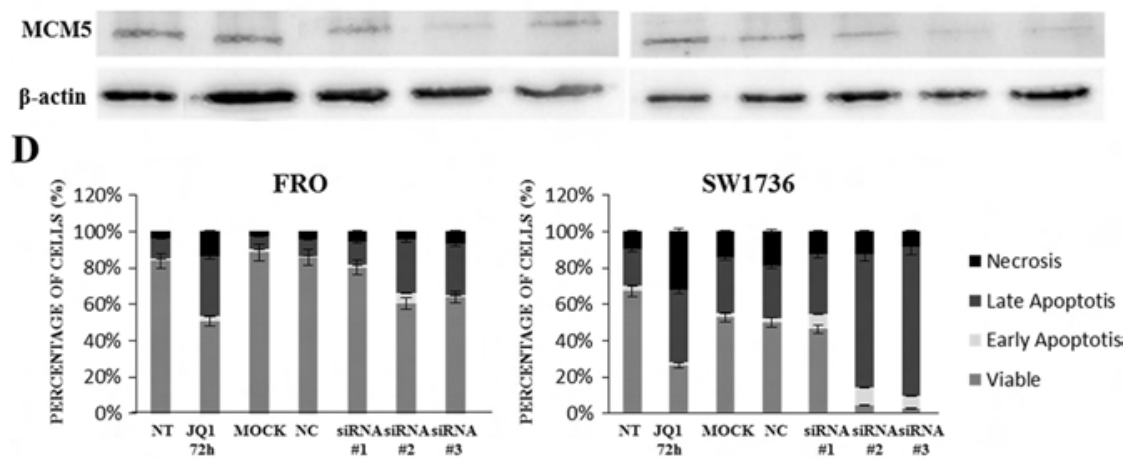

$\mathbf{E}$ FRO

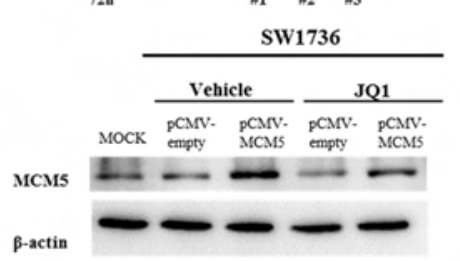

F

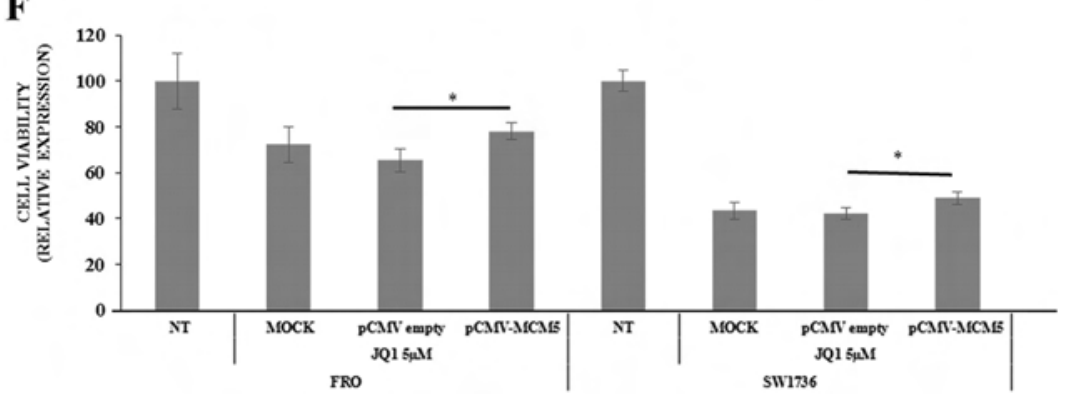

Figure 4

MCM5 is directly involved in BETis effects in human ATC cell lines. (A) BRD4 protein expression in ATC cell lines. (B) Chromatin was isolated from ATC cell lines and immunoprecipitated with BRD4 or IgG antibodies. MCM5 DNA was amplified using promoter-specific primers and analyzed by qPCR. All samples were run in triplicate. IgG immunoprecipitate was arbitrarily set at 1.0 and the enrichment was expressed as a relative expression value. An intergenic region (NCR) was used as an NC for BRD4 binding. (C) FRO and SW1736 cells were treated with nontargeting siRNA (NC) or three different siRNA sequences specific to MCM5 ( $5 \mathrm{nM})$. Cells were collected after $72 \mathrm{~h}$ treatment and MCM5 protein levels were analyzed. (D) FRO and SW1736 were exposed to either siRNA targeting MCM5 or NC for $72 \mathrm{~h}$ and apoptosis levels was analyzed by Annexin $V$ staining. (E) FRO and SW1736 cells were treated with pCMV empty vector (NC) or pCMV vector specific for MCM5 $(1.3 \mu \mathrm{g})$. Cells were collected after $48 \mathrm{~h}$ treatment and MCM5 protein levels were analyzed. (F) FRO and SW1736 were treated with $0.01 \mu \mathrm{g}$ p-CMV-MCM5 or empty vector and exposed to $5 \mu \mathrm{M}$ JQ1 or vehicle. Cell viability was determined by the MTT assay after $48 \mathrm{~h}$. NT was arbitrarily set at 100 and cell viability was expressed as a relative expression value. All samples were run in quadruplicate. Results are shown as mean \pm s.d. $* * * P<0.001$, $* * * * P<0.0001$ by ANOVA test. Data are representative of three independent experiments. coordinating origin activation and replication fork progression. MCM5 belongs to the minichromosome maintenance complex family, which has been associated with the highly proliferative phenotype of ATC (Guida et al. 2005). Several studies have established that MCM5 protein level is a good diagnostic marker of malignancy for bladder, esophageal, and gastric cancers (Kebebew et al. 2006). After confirming RNA-seq data on mRNA levels (Fig. 3A), we evaluated whether a $5 \mu \mathrm{M}$ JQ1 treatment significantly altered MCM5 protein levels in FRO and SW1736 cells (Fig. 3B). After 72 h incubation with JQ1, a significant reduction in MCM5 protein levels was observed (Fig. 3C). To extend and further validate this finding, we used two murine ATC cell lines derived from tumors developed by a genetically defined mouse model of ATC.
Treatment of both lines with $0.5 \mu \mathrm{M}$ JQ1 for $72 \mathrm{~h}$ resulted in a significant downregulation of Mcm5 RNA (Fig. 3D). To evaluate whether MCM5 is a direct target of BRD4, which is the BET protein whose activity is inhibited by JQ1, we performed a ChIP-qPCR analysis in FRO and SW1736 cells. We first evaluated if the two cell lines expressed comparable BRD4 protein levels (Fig. 4A). After the ChIP assay, we observed an average five-fold MCM5 enrichment in the BRD4 immunoprecipitate compared with the IgG one. To confirm specificity, an intergenic region has been used as an NC for BRD4 binding (Fig. 4B). In order to test the biological relevance of MCM5 gene repression upon BET inhibition, an RNA interference analysis was performed. MCM5 gene expression was silenced both in FRO and in SW1736 cells, and immunoblot analysis

Published by Bioscientifica Ltd 
Table 1 Top 20 most downregulated and upregulated genes.

\begin{tabular}{|c|c|c|}
\hline \multicolumn{3}{|c|}{ Downregulated genes } \\
\hline \multirow[b]{2}{*}{ Gene } & \multicolumn{2}{|c|}{ Log2 (fold_change) } \\
\hline & FRO & SW1736 \\
\hline E2F8 & -8.18691 & -3.32852 \\
\hline$I L 7 R$ & -7.92256 & -4.28496 \\
\hline SCG5 & -7.07872 & -5.36462 \\
\hline MFAP2 & -6.55018 & -4.00946 \\
\hline$K L F 17$ & -5.87194 & -2.54046 \\
\hline HAS2 & -5.61592 & -2.59963 \\
\hline SP140 & -5.51289 & -2.76406 \\
\hline SFTA1P & -4.86488 & -2.30007 \\
\hline APOL3 & -4.76234 & -3.04492 \\
\hline UHRF1 & -4.58863 & -2.45864 \\
\hline ELFN2 & -4.56104 & -2.07491 \\
\hline SLC38A5 & -4.50203 & -3.75806 \\
\hline WDR76 & -4.50144 & -3.32284 \\
\hline SEMAGB & -4.46547 & -2.00721 \\
\hline STAP2 & -4.43699 & -3.34008 \\
\hline$R F X 8$ & -4.42127 & -3.66572 \\
\hline$F M N L 1$ & -4.42127 & -2.04374 \\
\hline GINS2 & -4.3919 & -2.49012 \\
\hline HTR1D & -4.32174 & -3.30238 \\
\hline MCM5 & -4.27584 & -3.20364 \\
\hline
\end{tabular}

\begin{tabular}{|c|c|c|}
\hline \multicolumn{3}{|c|}{ Upregulated genes } \\
\hline \multirow[b]{2}{*}{ Gene } & \multicolumn{2}{|c|}{ Log2 (fold_change) } \\
\hline & FRO & SW1736 \\
\hline HIST2H2BE & 5.45681 & 6.36269 \\
\hline EFR3B & 5.45085 & 2.31549 \\
\hline HIST1H2BJ & 5.41635 & 4.29568 \\
\hline HIST1H2BC & 4.91188 & 3.90626 \\
\hline$A Q P 3$ & 4.82547 & 5.53788 \\
\hline KCNJ2-AS1 & 4.77102 & 2.57414 \\
\hline HIST1H2BD & 4.76918 & 7.37894 \\
\hline HIST1H1C & 4.65229 & 4.36823 \\
\hline MSS51 & 4.53001 & 4.03264 \\
\hline PROCA1 & 4.31851 & 2.40037 \\
\hline RNFT2 & 4.20444 & 2.75534 \\
\hline ARHGAP4 & 4.14859 & 2.29762 \\
\hline ALS2CR12 & 4.07061 & 5.36388 \\
\hline CLU & 4.06906 & 3.93869 \\
\hline HIST1H2AC & 3.98232 & 4.03878 \\
\hline BFSP1 & 3.77102 & 2.63104 \\
\hline ITPR1 & 3.6183 & 7.03299 \\
\hline FAM222A & 3.3286 & 2.436 \\
\hline TLL2 & 3.24364 & 2.56248 \\
\hline TM7SF2 & 3.20111 & 7.24837 \\
\hline
\end{tabular}

revealed an almost total abolishment of endogenous MCM5 protein level with siRNA\#2 treatment (Fig. 4C). Furthermore, MCM5 silencing, especially with siRNA\#2, significantly decreased cell viability $(P<0.001)$, increasing the percentage of apoptotic cells after Annexin V staining compared with NC (Fig. 4D). Similarly, to what we observed treating cells with JQ1, this outcome was more pronounced in SW1736 than in FRO cells. To further prove that MCM5 is directly involved in the cell viability decrease after $5 \mu \mathrm{M}$ JQ1 treatment, we performed a rescue experiment. FRO and SW1736 cells were treated with pCMV-MCM5 or NC and exposed to JQ1 for $48 \mathrm{~h}$. As shown in Fig. 4E, MCM5 protein overexpression partially rescued its protein levels in JQ1-treated cells. To validate that this phenomenon is associated with a cell viability rescue, an MTT assay was performed. FRO and SW1736 cells overexpressing MCM5 displayed a slight but significant reduction (10\% on average) of JQ1 effects when assessing cell viability (Fig. 4F). This mild rescue could be explained by the multitarget activity of BETis, whose effects are mediated by a remarkable number of actors, as we showed in our RNA-seq analysis (Fig. 2).

\section{In vivo MCM5-level evaluation}

Our data underline the relevance of MCM5 in thyroid cancer cell proliferation. Thus, MCM5 expression was evaluated in a panel of 12 NTs, 25 FAs, 23 FTCs, 36 PTCs, and 8 ATCs. Representative images of MCM5 staining are shown in Fig. 5A. MCM5 was faintly expressed in normal thyroid tissue and FAs. PTCs showed a dual behavior: some samples displayed an intense and high MCM5 nuclear staining, whereas some others a much lesser one, with only a cytoplasmic signal. In FTCs, nuclear staining was lesser intense and frequent, with a predominant cytoplasmic MCM5 staining. ATCs, instead, showed a marked nuclear MCM5 localization. No significant differences were observed in terms of MCM5 nuclear or cytoplasmic staining intensity among different areas of each tumor. Quantification of the nuclear immunohistochemical signal was obtained by computing the percentage of cell positivity and intensity of signal (Fig. 5B). As cytoplasmic MCM5 protein represents the inactive MCM5 isoform (Abe et al. 2012), the strong nuclear staining observed in all ATCs and several PTCs would indicate its hyperactivation. Finally, we measured the expression of Mcm5 in four primary ATCs developed by [Pten, Tp53] ${ }^{\text {thyr-I- }}$ mice (Antico Arciuch et al. 2011). In agreement with the human data, Mcm5 was found significantly overexpressed in mouse ATC, compared with normal thyroids (Fig. 5C), whereas its expression was not altered in FTCs developed by Pten $^{\text {thyr-l- }}$ mice (data not shown).

\section{Discussion}

The cross talk between genomic and epigenomic elements in driving generation and progression of both

Published by Bioscientifica Ltd 
A
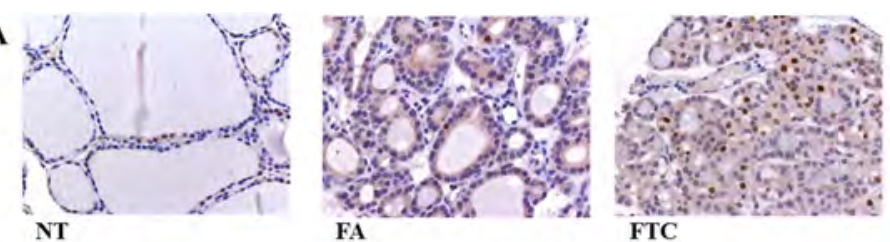

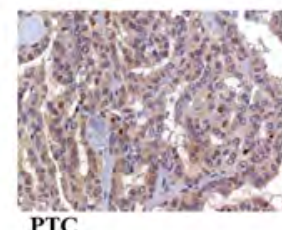

PTC
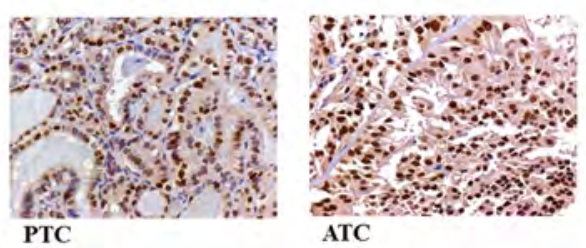

B

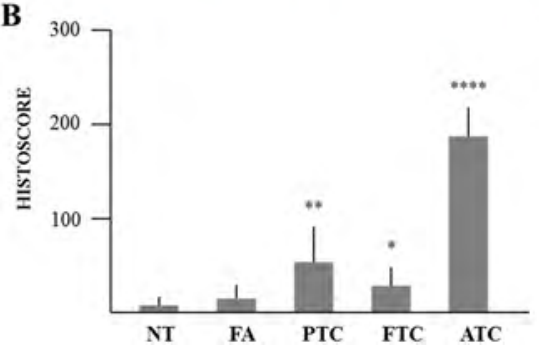

C

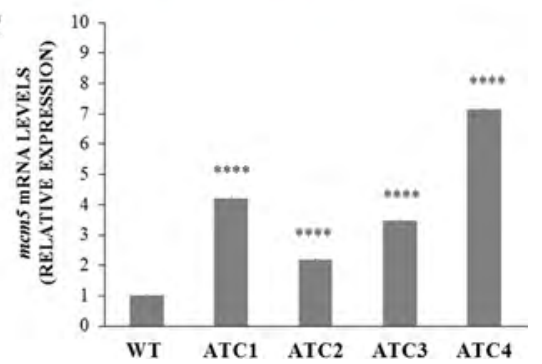

Figure 5

MCM5 expression in thyroid tumors. (A) Representative images of MCM5 expression in NTs, FAs, PTCs, FTCs, and ATCs. (B) Quantitation of MCM5 expression in normal and neoplastic thyroid tissues. Quantitation was obtained by using the IHC score, calculated as described in Materials and methods section. (C) Mcm5 expression was evaluated by qPCR in control thyroids from wild-type mice and primary ATCs from [Pten, Tp53 $]^{\text {thyr-l- }}$ mice. All samples were run in triplicate. Wild-type (WT) expression was set at 1.0 and mRNA levels are expressed as relative expression values. Results are shown as mean \pm S.D. ${ }^{*} P<0.05, * * P<0.01, * * * * P<0.0001$ by ANOVA test. hematologic malignancies and solid tumors has been extensively highlighted (Martín-Subero et al. 2013). Among epigenetic anticancer drugs, those targeting BET proteins have recently emerged as promising therapeutics in a remarkable range of diseases (Shi \& Vakoc 2014, Wee et al. 2014). ATC is the most aggressive thyroid cancer subtype and it does not significantly respond to any therapy. In order to find new strategies to treat this aggressive thyroid cancer subtype, we investigated BETis target genes in ATC cell lines. As expected, human ATC cell lines FRO and SW1736, treated with three different BETis, displayed a decrease in cell viability associated with an increase in cell death phenomena. These data were also been confirmed in a third ATC cell line (Supplementary Fig. 3). In our experimental model, BET inhibition triggers a multitarget cascade resulting in substantial biological effects, as demonstrated by RNA-seq data. The identification of genes mediating BETis antiproliferative effect could provide innovative therapeutic targets. Among hundreds of deregulated genes after BET inhibition, a large fraction belongs to the regulators of cell cycle and apoptosis, that is, E2F family members, CDKs and CDK inhibitors, and other TP53 pathway-related elements (Møller 2003, Smallridge et al. 2009). These data are similar to those previously published for study in medulloblastoma and metastatic melanoma (Henssen et al. 2013, Segura et al. 2013). All these findings corroborate the hypothesis that BETis disrupt cell cycle control, driving G0/G1 arrest and inducing cell death, by acting on multiple targets. Ott and coworkers observed that JQ1 treatment decrease the expression of IL7R in leukemic cell lines, at both mRNA and protein levels (Ott et al. 2012). In anaplastic thyroid cell lines, a $24 \mathrm{~h}$ JQ1 treatment exhibited a significant downregulation of $I L 7 R$ mRNA levels, but this reduction was not confirmed by analyzing protein levels (Supplementary Fig. 5). We would like to stress that endogenous IL7R protein is not so abundant in these two cell lines; therefore, the misregulation of a protein involved during lymphocyte development seems not to perform a substantial role in JQ1 effects in thyroid cancer cells. Our data, instead, show at least a ten-fold downregulation of MCM5 expression in JQ1-treated cells, suggesting a critical role of this protein in the molecular cascade triggered by BETis. As confirmation, MCM5 proved to be a direct target of BRD4, as highlighted in the ChIP-qPCR assay. Moreover, MCM5 overexpression moderately attenuated FRO and SW1736 JQ1 sensitivity, in terms of cell viability, as shown in the rescue experiment (Fig. 4F). This mild effect is reasonably due to the multitarget activity of epigenetic drugs, which act simultaneously on a wide range of pathways, as shown in our RNA-seq analysis. Accordingly to our data, poor rescue effects have been obtained for other targets of BETis (Lockwood et al. 2012, Bandopadhayay et al. 2014).

MCM5 belongs to the minichromosome maintenance complex, which includes elements of the pre-replicative complex that are essential for DNA replication (Noseda \& Karsan 2006). MCM proteins are considered as licensing

Published by Bioscientifica Ltd. 
components for the S-phase initiation. MCMs oscillate between nuclear and cytoplasmic localizations (Madine et al. 2000). Nuclear MCMs associate with DNA during G1 and early S-phase, allowing the control of replication origin firing, in order to restrict the chromosome replication to only one round per cell cycle (Romanowski \& Madine 1997). MCMs are restricted, instead, to cytoplasm during G2/M-phase in order to prevent re-replication phenomena (Laskey 2005). Recently, components of the MCM family have been described as aberrantly expressed in many malignancies, including thyroid carcinomas (Giaginis et al. 2010). In agreement with these findings and corroborating our in vitro and in vivo results, MCM5 immunostaining demonstrated that ATCs contained more MCM5-positive cells than did normal thyroid gland (Fig. 5).
Several studies have demonstrated that the expression of MCM5 is controlled by different pathways (Guida et al. 2005, Laskey 2005, Noseda \& Karsan 2006, Abe et al. 2012). Fig. 6 summarizes major players controlling MCM5 gene expression, as well as their functional interactions. By comparing Fig. 6 and Supplementary Table 4, it is undeniable that many proteins that upregulate MCM5 expression are also downregulated by BETis. Interestingly, JQ1 reduces the expression of some elements involved in the replication fork assembly, thus affecting cell cycle mechanisms, in which, in turn, MCM proteins are involved. Altogether, this cascade could lead to G0/G1 arrest (Fig. 1D) and cell death. In conclusion, our findings support the hypothesis that MCM5 targeting may be regarded as an effective molecular therapy against ATC.

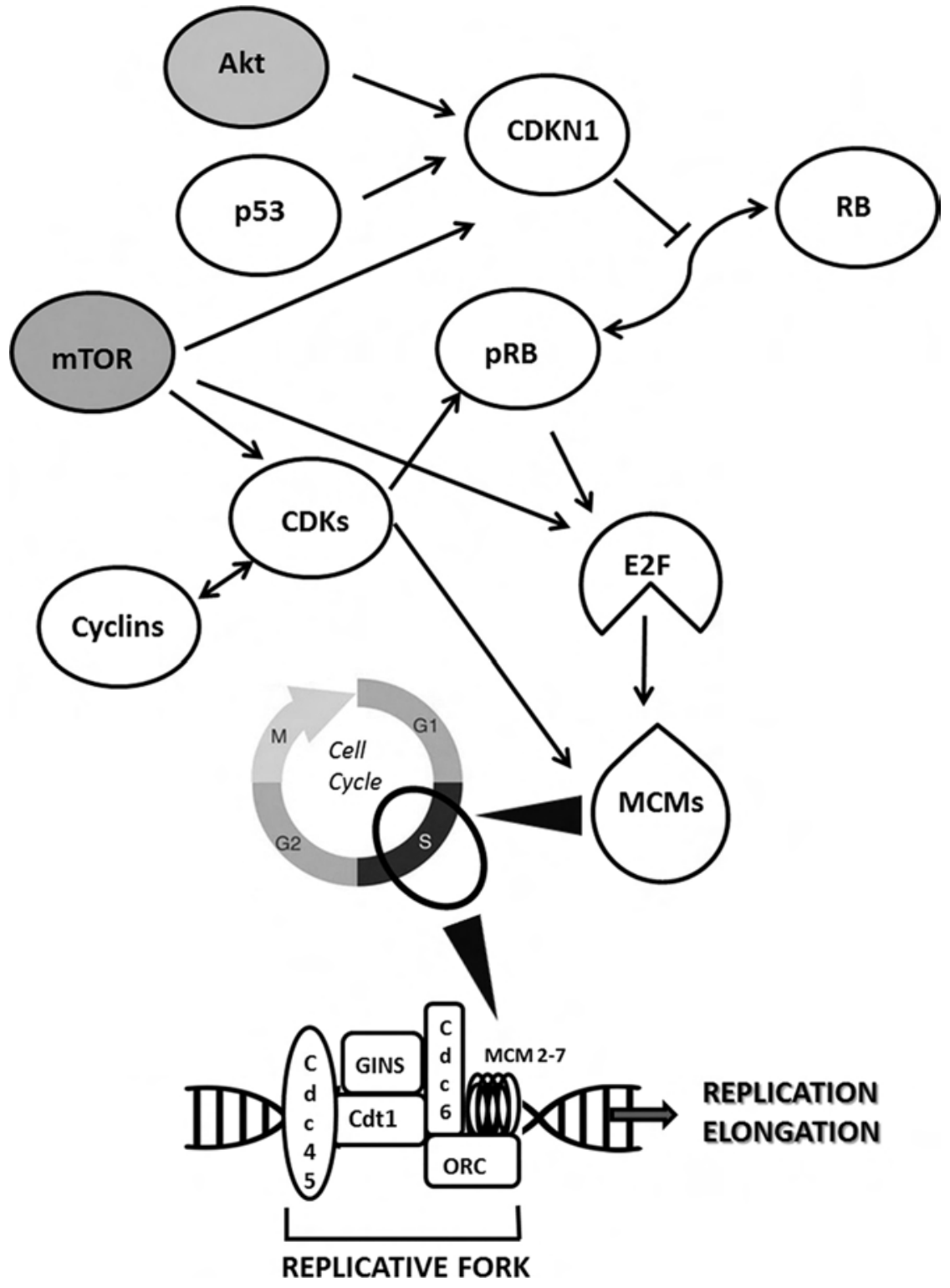

Figure 6

Biological network related to MCM protein function. Network diagram (upper part) showing key molecules controlling MCM protein levels. White symbols represent proteins whose mRNA levels are modulated by BETis in our transcriptome analysis (see Supplementary Table 4); gray symbols indicate proteins whose mRNA levels are not modulated by BETis. Arrows indicate functional relationship between proteins (delineated in Madine et al. 2000, Guida et al. 2005, Laskey 2005, Abe et al. 2012). The lower part indicates factors cooperating with MCM proteins in the replicative fork assembly. All of these factors are downregulated by BETis (see Supplementary Table 4). Arrowheads show the relationship between MCMs and cell cycle phases. 


\section{Supplementary data}

This is linked to the online version of the paper at http://dx.doi.org/10.1530/ ERC-15-0322.

\section{Declaration of interest}

The authors declare that there is no conflict of interest that could be perceived as prejudicing the impartiality of the research reported.

\section{Funding}

This work was supported by grants to G D from Associazione Italiana per la Ricerca sul Cancro (AIRC) (project $n$ IG 10296) and from Ministero degli Affari Esteri of Italy (Progetti grande rilevanza 2016, project n PGR02954), to A D C from the National Institutes of Health (CA128943 and CA172012).

\section{References}

Abe S, Kurata M, Suzuki S, Yamamoto K, Aisaki K, Kanno J \& Kitagawa M 2012 Minichromosome maintenance 2 bound with retroviral Gp70 is localized to cytoplasm and enhances DNAdamage-induced apoptosis. PLoS One 7 40129. (doi:10.1371/journal. pone.0040129)

Alderton GK 2011 Targeting MYC? You BET. Nature Reviews Drug Discovery 10 732-733. (doi:10.1038/nrd3569)

Antico Arciuch VG, Dima M, Liao XH, Refetoff S \& Di Cristofano A 2010 Cross-talk between PI3K and estrogen in the mouse thyroid predisposes to the development of follicular carcinomas with a higher incidence in females. Oncogene 29 5678-5686. (doi:10.1038/ onc.2010.308)

Antico Arciuch VG, Russo MA, Dima M, Kang KS, Dasrath F, Liao XH, Refetoff S, Montagna C \& Di Cristofano A 2011 Thyrocyte-specific inactivation of p53 and Pten results in anaplastic thyroid carcinomas faithfully recapitulating human tumors. Oncotarget 2 1109-1126. (doi:10.18632/oncotarget.380)

Arturi F, Russo D, Giuffrida D, Schlumberger M \& Filetti S 2000 Sodium-Iodide symporter (NIS) gene expression in lymph node metastases of papillary thyroid carcinomas. European Journal of Endocrinology 143 623-627. (doi:10.1530/eje.0.1430623)

Baldan F, Lavarone E, Di Loreto C, Filetti S, Russo D, Damante G \& Puppin C 2014 Histone post-translational modifications induced by histone deacetylase inhibition in transcriptional control units of NIS gene. Molecular Biology Reports 41 5257-5265. (doi:10.1007/ s11033-014-3397-x)

Baldan F, Mio C, Lavarone E, Di Loreto C, Puglisi F, Damante G \& Puppin C 2015 Epigenetic bivalent marking is permissive to the synergy of HDAC and PARP inhibitors on TXNIP expression in breast cancer cells. Oncology Reports 33 2199-2206. (doi:10.3892/ or.2015.3873)

Bandopadhayay P, Bergthold G, Nguyen B, Schubert S, Gholamin S, Tang Y, Bolin S, Schumacher SE, Zeid R, Masoud S, et al. 2014 BET bromodomain inhibition of $M Y C$-amplified medulloblastoma. Clinical Cancer Research 20 912-925. (doi:10.1158/1078-0432.CCR-13-2281)

Chaitanya GV, Steven AJ \& Babu PP 2010 PARP-1 cleavage fragments: signatures of cell-death proteases in neurodegeneration. Cell Communication and Signaling 22 31. (doi:10.1186/1478-811X-8-31)

Chiang CM 2009 Brd4 engagement from chromatin targeting to transcriptional regulation: selective contact with acetylated histone H3 and H4. F1000 Biology Reports 1 98. (doi:10.3410/B1-98)
Da Costa D, Agathanggelou A, Perry T, Weston V, Petermann E, Zlatanou A, Oldreive C, Wei W, Stewart G, Longman J, et al. 2013 BET inhibition as a single or combined therapeutic approach in primary paediatric B-precursor acute lymphoblastic leukaemia. Blood Cancer Journal 3 e126. (doi:10.1038/bcj.2013.24)

Dawson MA, Kouzarides T \& Huntly BJ 2012 Targeting epigenetic readers in cancer. New England Journal of Medicine 367 647-657. (doi:10.1056/NEJMra1112635)

Durante C, Haddy N, Baudin E, Leboulleux S, Hartl D, Travagli JP, Caillou B, Ricard M, Lumbroso JD, De Vathaire F, et al. 2006 Longterm outcome of 444 patients with distant metastases from papillary and follicular thyroid carcinoma: Benefits and limits of radioiodine therapy. Journal of Clinical Endocrinology and Metabolism 912892 2899. (doi:10.1210/jc.2005-2838)

Elisei R 2012 Anaplastic thyroid cancer therapy: dream or reality? Endocrine 42 468-470. (doi:10.1007/s12020-012-9785-x)

Falahi F, Sgro A \& Blancafort P 2015 Epigenome engineering in cancer: fairytale or a realistic path to the clinic? Frontiers in Oncology 5 22. (doi:10.3389/fonc.2015.00022)

Filippakopoulos P, Qi J, Picaud S, Shen Y, Smith WB, Fedorov O, Morse EM, Keates T, Hickman TT, Felletar I, et al. 2010 Selective inhibition of BET bromodomains. Nature 468 1067-1073. (doi:10.1038/nature09504)

Giaginis C, Vgenopoulou S, Vielh P \& Theocharis S 2010 MCM proteins as diagnostic and prognostic tumor markers in the clinical setting. Histology and Histopathology 25 351-370.

Gobeil S, Boucher CC, Nadeau D \& Poirier GG 2001 Characterization of the necrotic cleavage of poly(ADP-ribose) polymerase (PARP-1): implication of lysosomal proteases. Cell Death \& Differentiation 8 588-894. (doi:10.1038/sj.cdd.4400851)

Guida T, Salvatore G, Faviana P, Giannini R, Garcia-Rostan G, Provitera L, Basolo F, Fusco A, Carlomagno F \& Santoro M 2005 Mitogenic effects of the up-regulation of minichromosome maintenance proteins in anaplastic thyroid carcinoma. Journal of Clinical Endocrinology and Metabolism 90 4703-4709. (doi:10.1210/ jc.2004-2459)

Henssen A, Thor T, Odersky A, Heukamp L, El-Hindy N, Beckers A, Speleman F, Althoff K, Schäfers S, Schramm A, et al. 2013 BET bromodomain protein inhibition is a therapeutic option for medulloblastoma. Oncotarget 4 2080-2095. (doi:10.18632/ oncotarget.1534)

Kebebew E, Peng M, Reiff E, Duh QY, Clark OH \& McMillan A 2006 Diagnostic and prognostic value of cell-cycle regulatory genes in malignant thyroid neoplasms. World Journal of Surgery 30 767-774. (doi:10.1016/j.surg.2006.07.038)

Laskey R 2005. The Croonian Lecture 2001 hunting the antisocial cancer cell: MCM proteins and their exploitation. Philosophical Transactions of the Royal Society of London B: Biological Science $\mathbf{3 6 0}$ 1119-1132. (doi:10.1098/rstb.2005.1656)

Lockwood WW, Zejnullahu K, Bradner JE \& Varmus H 2012 Sensitivity of human lung adenocarcinoma cell lines to targeted inhibition of BET epigenetic signaling proteins. PNAS 109 19408-19413. (doi:10.1073/pnas.1216363109)

Madine MA, Swietlik M, Pelizon C, Romanowski P, Mills AD \& Laskey RA 2000 The roles of the MCM, ORC, and Cdc6 proteins in determining the replication competence of chromatin in quiescent cells. Journal of Structural Biology 129 198-210. (doi:10.1006/ jsbi.2000.4218)

Martín-Subero JI, López-Otín C \& Campo E 2013 Genetic and epigenetic basis of chronic lymphocytic leukemia. Current Opinion in Hematology 20 362-368. (doi:10.1097/MOH.0b013e32836235dc)

Møller MB 2003 Molecular control of the cell cycle in cancer: biological and clinical aspects. Danish Medical Bulletin 50 118-138.

Nicodeme E, Jeffrey KL, Schaefer U, Beinke S, Dewell S, Chung CW, Chandwani R, Marazzi I, Wilson P, Coste H, et al. 2010 Suppression http://erc.endocrinology-journals.org

DOI: 10.1530/ERC-15-0322
(C) 2016 Society for Endocrinology Printed in Great Britain 
of inflammation by a synthetic histone mimic. Nature 4681119 1123. (doi:10.1038/nature09589)

Noseda M \& Karsan A 2006 Notch and minichromosome maintenance (MCM) proteins: integration of two ancestral pathways in cell cycle control. Cell Cycle 5 2704-2709. (doi:10.1038/nature15372)

Ott CJ, Kopp N, Bird L, Paranal RM, Qi J, Bowman T, Rodig SJ, Kung AL, Bradner JE \& Weinstock DM 2012 BET bromodomain inhibition targets both c-Myc and IL7R in high-risk acute lymphoblastic leukemia. Blood 120 2843-2852. (doi:10.1182/blood-2012-02-413021)

Passon N, Gerometta A, Puppin C, Lavarone E, Puglisi F, Tell G, Di Loreto C \& Damante G 2012 Expression of Dicer and Drosha in triple-negative breast cancer. Journal of Clinical Pathology 65 320-326. (doi:10.1136/jclinpath-2011-200496)

Patel KN \& Shaha AR 2014 Poorly differentiated thyroid cancer. Current Opinion in Otolaryngology-Head \& Neck Surgery 22 121-126. (doi:10.1097/MOO.0000000000000037)

Perri F, Lorenzo GD, Scarpati GD \& Buonerba C 2011 Anaplastic thyroid carcinoma: a comprehensive review of current and future therapeutic options. World Journal of Clinical Oncology 2 150-157. (doi:10.5306/wjco.v2.i12.377)

Pilli T, Prasad KV, Jayarama S, Pacini F \& Prabhakar BS 2009 Potential utility and limitations of thyroid cancer cell lines as models for studying thyroid cancer. Thyroid 19 1333-1342. (doi:10.1089/ thy.2009.0195)

Puppin C, D'Aurizio F, D'Elia AV, Cesaratto L, Tell G, Russo D, Filetti S, Ferretti E, Tosi E, Mattei T, et al. 2005 Effects of histone acetylation on NIS promoter and expression of thyroid-specific transcription factors. Endocrinology 146 3967-3974. (doi:10.1210/en.2005-0128)

Romanowski P \& Madine MA 1997 Mechanisms restricting DNA replication to once per cell cycle: The role of Cdc6p and ORC. Trends in Cell Biology 7 9-10. (doi:10.1016/S0962-8924(97)30077-4)

Russo D, Durante C, Bulotta S, Puppin C, Puxeddu E, Filetti S \& Damante G 2013 Targeting histone deacetylase in thyroid cancer. Expert Opinion on Therapetic Targets 17 179-193. (doi:10.1517/147282 22.2013.740013)

Schlumberger M, Lacroix L, Russo D, Filetti S \& Bidart JM 2007 Defects in iodide metabolism in thyroid cancer and implications for the follow-up and treatment of patients. Nature Clinical Practice Endocrinology \& Metabolism 3 260-269. (doi:10.1038/ ncpendmet0449)
Schweppe RE, Klopper JP, Korch C, Pugazhenthi U, Benezra M, Knauf JA, Fagin JA, Marlow LA, Copland JA, Smallridge RC, et al. 2008 Deoxyribonucleic acid profiling analysis of 40 human thyroid cancer cell lines reveals cross-contamination resulting in cell line redundancy and misidentification. Journal of Clinical Endocrinology and Metabolism 93 4331-4341. (doi:10.1210/jc.2008-1102)

Segura MF, Fontanals-Cirera B, Gaziel-Sovran A, Guijarro MV, Hanniford D, Zhang G, González-Gomez P, Morante M, Jubierre L, Zhang W, et al. 2013 BRD4 sustains melanoma proliferation and represents a new target for epigenetic therapy. Cancer Research 73 6264-6276. (doi:10.1158/0008-5472. CAN-13-0122-T)

Shi J \& Vakoc CR 2014 The mechanisms behind the therapeutic activity of BET bromodomain inhibition. Molecular Cell 54 728-736. (doi:10.1016/j.molcel.2014.05.016)

Smallridge RC, Marlow LA \& Copland JA 2009 Anaplastic thyroid cancer: molecular pathogenesis and emerging therapies. Endocrine-Related Cancer 16 17-44. (doi:10.1677/ERC-08-0154)

Trapnell C, Roberts A, Goff L, Pertea G, Kim D, Kelley DR. Pimentel H, Salzberg SL, Rinn JL \& Pachter L 2012 Differential gene and transcript expression analysis of RNA-seq experiments with TopHat and Cufflinks. Nature Protocols 7 562-578. (doi:10.1038/nprot.2012.016)

Vezzi F, Del Fabbro C, Tomescu AI \& Policriti A 2012 rNA: a fast and accurate short reads numerical aligner. Bioinformatics 28 123-124. (doi:10.1093/bioinformatics/btr617)

Wee S, Dhanak D, Li H, Armstrong SA, Copeland RA, Sims R, Baylin SB, Liu XS \& Schweizer L 2014 Targeting epigenetic regulators for cancer therapy. Annuals of the New York Academy of Science 1309 30-36. (doi:10.1111/nyas.12356)

Yeager N, Klein-Szanto A, Kimura S \& Di Cristofano A 2007 Pten loss in the mouse thyroid causes goiter and follicular adenomas: insights into thyroid function and Cowden disease pathogenesis. Cancer Research 67 959-966. (doi:10.1158/0008-5472. CAN-06-3524)

Zuber J, Rappaport AR, Luo W, Wang E, Chen C, Vaseva AV, Shi J, Weissmueller S, Fellmann C, Taylor MJ, et al. 2011 An integrated approach to dissecting oncogene addiction implicates a Mybcoordinated self-renewal program as essential for leukemia maintenance. Genes Development 25 1628-1640. (doi:10.1101/ gad.17269211)

Received in final form 15 February 2016

Accepted 24 February 2016

Accepted Preprint published online 24 February 2016
(C) 2016 Society for Endocrinology Printed in Great Britain
Published by Bioscientifica Ltd 